EXTENDED REPORT

\title{
Muscle strength, pain, and disease activity explain individual subdimensions of the Health Assessment Questionnaire disability index, especially in women with rheumatoid arthritis
}

\author{
A Häkkinen, H Kautiainen, P Hannonen, J Ylinen, H Mäkinen, T Sokka
}

See end of article for authors' affiliations

Correspondence to: Dr Arja Häkkinen, Department of Physical Medicine and

Rehabilitation, Jyväskylä Central Hospital, 40620 Jyväskylä, Finland; arja. hakkinen@ksshp.fi

Accepted 16 May 2005

Published Online First 18 May 2005

\begin{abstract}
Objective: To study the extent to which muscle strength and performance, pain, and disease activity are associated with the total Health Assessment Questionnaire (HAQ) disability index and its subdimensions in male and female patients with rheumatoid arthritis.

Methods: HAQ for functional capacity was completed by 135 patients with rheumatoid arthritis referred for orthopaedic surgery (74\% women; mean (SD) age 62 (10) years; disease duration 19 (13) years, 70\% positive for rheumatoid factor). Knee extension, trunk extension and flexion, grip strength, walking speed, and sit-to-stand test were measured to mirror physical function. Radiographs of hands and feet, pain, and the modified 28 joint disease activity score (DAS28) were also assessed.

Results: Mean total HAQ was $1.08(0.68)$ in women and $0.67(0.70)$ in men $(p=0.0031)$. Women had greater disability than men in five of the eight subdimensions of the HAQ. Grip strength was $48 \%$, knee extension strength $46 \%$, trunk extension strength $54 \%$, and trunk flexion strength $43 \%$ lower in women than in men. Knee extension strength was inversely correlated with walking time $(r=-0.63$ (95\% confidence interval, -0.73 to -0.51$))$ and with sit-to-stand test $(r=-0.47(-0.60$ to -0.31$))$. In an ordered logistic regression analysis in female rheumatoid patients, DAS28, pain, knee extension strength, and grip strength were associated with the total HAQ disability index.

Conclusions: Women reported greater disability than men both in the total HAQ and in the majority of its eight subdimensions. In addition to disease activity and pain, muscle strength has a major impact on disability especially in female rheumatoid patients.
\end{abstract}

A fter reaching a peak in early adult years, skeletal muscle gradually declines beginning at about 45 years. ${ }^{1-4}$ Linked to the age related decrease in muscle mass, which is commonly referred sarcopenia, is a reduction in muscle strength. ${ }^{5-9}$ Rall and Roubenoff ${ }^{10}$ have reported that inflammation in rheumatoid arthritis leads to loss of metabolically active tissue, and fat mass tends to increase. This situation, termed "rheumatoid cachexia", may aggravate the condition and lead to physical inactivity, diminished strength, and decreased functional status. Muscle weakness is a common sign in rheumatoid arthritis. Compared with healthy controls, reductions of $25-50 \%$ in muscle strength in rheumatoid patients in American Rheumation Association (ARA) functional class II have been found. ${ }^{11-13}$ In more severe rheumatoid arthritis, reductions in muscle strength of up to $70 \%$ have been reported. ${ }^{14}$ Muscle weakness is usually considered to be a result of disuse atrophy, because patients' normal activities are impeded by systemic inflammation as well as by joint pain and by the damage characteristic of rheumatoid arthritis.

Several studies have show that the total HAQ score reflects disease activity, and is associated with pain, swollen and tender joint counts, and laboratory measures mirroring inflammatory activity. ${ }^{15-17}$ To a lesser extent, the HAQ is also associated with radiographic damage of joints. ${ }^{15} 161819$ While associations of various clinical variables with HAQ have usually been reported, little is known about the influence of muscle performance on the HAQ. Stucki et al have reported a significant correlation between HAQ and muscle strength index measured by a hand held pull gauge. ${ }^{20}$ As the HAQ assesses fine movements of the upper extremities, locomotor activities of the lower extremities, and activities involving both the upper and lower extremities and the trunk, the contributions of the different muscle groups to physical function measured by the HAQ need to be studied separately.

Our aim in this study was therefore to explore in more detail the associations of muscle strength and muscle performance measured by walking speed and sit-to-stand tests with the total HAQ disability index and its subdimensions in male and female patients with longstanding rheumatoid arthritis.

\section{METHODS}

From among 194 patients with rheumatoid arthritis who had been referred to the waiting list for orthopaedic surgery at Jyväskylä Central Hospital, serving a population of 265000 , 135 volunteered for the present study and were referred to a physiotherapist for measurement of physical function. The mean (SD) age of the patients was $62(10)$ years and 100 $(74 \%)$ of them were female. At the check up visit $82 \%$ of the patients were being treated with disease modifying antirheumatic drugs (DMARDs). Low dose prednisolone was employed in $42 \%$ and pain relieving drugs (at least once or twice a week) in $73 \%$. Of the women, $28 \%$ were waiting for upper extremity surgery, $58 \%$ for lower extremity surgery, and $14 \%$ for other surgery. In men the corresponding figures were $37 \%, 43 \%$, and $20 \%$. However, not all the surgical interventions were for rheumatoid arthritis.

Functional status in the activities of daily living was assessed by the Finnish version of the $\mathrm{HAQ}^{21}$ which included 20 questions in eight subdimensions: (1) dressing and grooming, (2) arising, (3) eating, (4) walking, (5) hygiene, (6) reach, (7)

Abbreviations: ARA, American Rheumation Association; DAS28, 28 joint disease activity score; $H A Q$, Health Assessment Questionnaire; VAS, visual analogue scale 
Table 1 Demographic variables and clinical and radiographic characteristics of 135 patients with rheumatoid arthritis

\begin{tabular}{|c|c|c|c|}
\hline Variable & Male $(n=35)$ & Female $(n=100)$ & p Value \\
\hline \multicolumn{4}{|l|}{ Demographic variables } \\
\hline Age (years) (mean (SD)) & $62(11)$ & $61(10)$ & 0.71 \\
\hline RF present (\%) (mean (SD)) & $25(71)$ & $70(70)$ & 0.99 \\
\hline Duration of disease (years) (mean (range)) & 19 (0 to 54$)$ & 19 (1 to 50$)$ & 0.95 \\
\hline \multicolumn{4}{|l|}{ Measures of disease activity } \\
\hline $\mathrm{ESR}(\mathrm{mm} / \mathrm{h})$ (median (IQR)) & 17 (8 to 37$)$ & $18(10$ to 31$)$ & 0.76 \\
\hline Swollen joint count (28) (median (range)) & $0(0$ to 10$)$ & $0(0$ to 14$)$ & 0.25 \\
\hline Tender joint count (28) (median (range) & $0(0$ to 8$)$ & $0(0$ to 14$)$ & 0.085 \\
\hline Patient's overall assessment (VAS) (median (IQR)) & 33 (19 to 51$)$ & $48(31$ to 58$)$ & 0.010 \\
\hline Pain (VAS) (median (IQR)) & 31 (18 to 62$)$ & 55 (33 to 70$)$ & 0.006 \\
\hline Morning stiffness (median (IQR)) & 59 (15 to 83$)$ & $60(12$ to 120$)$ & 0.42 \\
\hline DAS28 (mean (SD)) & $2.79(1.16)$ & $3.19(1.04)$ & 0.059 \\
\hline \multicolumn{4}{|l|}{ Radiographic variables } \\
\hline Erosion present (n (\%)) & $29(83)$ & $83(83)$ & 0.99 \\
\hline
\end{tabular}

grip, and (8) common daily activities. The response alternatives were $0=$ able without any difficulty, $1=$ able with some difficulty, $2=$ able with much difficulty, and $3=$ unable. The highest response within each subdimension was used as a score for that function and the total HAQ score ranged from 0 to 3 .

Maximum walking speed was measured by light cells over a distance of $10 \mathrm{~m}$. Chair rise time (s) was measured using a $43 \mathrm{~cm}$ high chair with five repetitions. ${ }^{22}$ The maximum unilateral isometric strength of the knee extensors was measured using a David 200 dynamometer (Outokumpu, Finland). ${ }^{23}$ Maximum isometric forces of the trunk flexors and extensors were measured by an isometric strain gauge dynamometer. ${ }^{24}$ A Jamar standard dynamometer was used to measure isometric grip strength. ${ }^{25}$ The means for knee extension and grip strength on the right and left side were taken for the subsequent analysis.
Erosions in radiographs of hands and feet were analysed by TS without knowledge of the identity of the patients at the time of reading. Overall pain was assessed on a $100 \mathrm{~mm}$ visual analogue scale (VAS). ${ }^{26}$ The modified 28 joint disease activity score (DAS28)-including 28 tender and swollen joint counts, patient's self report global status on VAS, and the erythrocyte sedimentation rate (ESR)—was used to evaluate clinical disease activity. ${ }^{27}$

The ethics committee of Jyväskylä Central Hospital approved the study, and the patients participating gave a written informed consent.

\section{Statistical methods}

Variables with a normal distribution were expressed as mean (SD); statistical comparisons between the measures or groups were done using the $t$ test and analysis of variance (ANOVA).

\begin{tabular}{|c|c|c|c|}
\hline Subdimension with items & $\begin{array}{l}\text { Male } \\
\text { (mean (SD)) }\end{array}$ & $\begin{array}{l}\text { Female } \\
\text { (mean (SD)) }\end{array}$ & p Value* \\
\hline Dressing and grooming: & & & 0.45 \\
\hline Dress yourself, including shoelaces and buttons? & $0.69(0.76)$ & $0.81(0.60)$ & \\
\hline Shampoo your hair? & $0.37(0.69)$ & $0.54(0.69)$ & \\
\hline Arising: & & & 0.40 \\
\hline Stand up from a straight chair? & $0.69(0.96)$ & $0.68(0.80)$ & \\
\hline Get in and out of bed? & $0.46(0.61)$ & $0.58(0.62)$ & \\
\hline Eating: & & & $<0.001$ \\
\hline Cut your meat? & $0.43(0.66)$ & $0.88(0.88)$ & \\
\hline Lift a full cup or glass to your mouth? & $0.37(0.65)$ & $0.42(0.67)$ & \\
\hline Open a new milk cartoon? & $0.49(0.66)$ & $1.08(0.88)$ & \\
\hline Walking: & & & 0.15 \\
\hline Walk outdoors on flat ground? & $0.57(0.70)$ & $0.63(0.66)$ & \\
\hline Climb up five steps? & $0.46(0.74)$ & $0.72(0.77)$ & \\
\hline Hygiene: & & & 0.021 \\
\hline Wash and dry your body? & $0.60(0.85)$ & $0.69(0.73)$ & \\
\hline Take a tub bath? & $0.83(1.07)$ & $1.47(1.22)$ & \\
\hline Get on and off the toilet? & $0.40(0.55)$ & $0.49(0.61)$ & \\
\hline Reach: & & & 0.0017 \\
\hline $\begin{array}{l}\text { Reach and get down a } 2 \mathrm{~kg} \text { object from above your head? } \\
\text { Bend down to pick up clothing from the floor? }\end{array}$ & $0.54(0.82)$ & $\begin{array}{l}1.22(1.02) \\
0.63(0.72)\end{array}$ & \\
\hline $\begin{array}{l}\text { Bend down to pick up clothing from the floor? } \\
\text { Grip: }\end{array}$ & $0.5 /(0.70)$ & $0.63(0.12)$ & 0.0024 \\
\hline Open car doors? & $0.37(0.65)$ & $0.90(0.75)$ & \\
\hline Open previously open jars? & $0.23(0.43)$ & $0.54(0.69)$ & \\
\hline Turn faucets on and off? & $0.23(0.43)$ & $0.39(0.60)$ & \\
\hline Common daily activities: & & & 0.014 \\
\hline Run errands and shop? & $0.34(0.54)$ & $0.65(0.73)$ & \\
\hline Get in and out of a car? & $0.43(0.61)$ & $0.77(0.60)$ & \\
\hline Do chores such as vacuuming or garden work? & $0.60(0.81)$ & $1.16(0.94)$ & \\
\hline
\end{tabular}


Table 3 Muscle strength in male and female patients with rheumatoid arthritis

\begin{tabular}{|c|c|c|c|c|c|}
\hline \multirow[b]{2}{*}{ Variable } & \multicolumn{2}{|l|}{ Men } & \multicolumn{2}{|l|}{ Women } & \multirow[b]{2}{*}{ p Value } \\
\hline & Mean (SD) & Range & Mean (SD) & Range & \\
\hline $\begin{array}{l}\text { Grip strength* } \\
<0.001\end{array}$ & 279 (129) & 54 to 608 & $146(89)$ & 0 to 378 & \\
\hline $\begin{array}{l}\text { Knee extension strength* } \\
<0.001\end{array}$ & 331 (128) & 130 to 636 & $180(70)$ & 13 to 411 & \\
\hline $\begin{array}{l}\text { Trunk extension } \\
<0.001\end{array}$ & $454(220)$ & 138 to 1017 & $241(111)$ & 29 to 559 & \\
\hline $\begin{array}{l}\text { Trunk flexion } \\
<0.001\end{array}$ & 440 (155) & 170 to 928 & 249 (87) & 80 to 567 & \\
\hline
\end{tabular}

If the variables did not have a normal distribution or ordinal, then descriptive values were expressed as medians with interquartile ranges (IQR) or ranges; statistical comparisons between groups were done by using the Mann-Whitney test and a multivariate Hotelling-type permutation test. Measures with a discrete distribution were expressed as counts (\%) and analysed by $\chi^{2}$ test or Fischer's exact test.

Associations between disability (HAQ) and the physical function and disease activity indices were analysed using forward stepwise ordered logit models. Correlation coefficients were calculated by the Spearman method. The multiple imputation method (Markov chain Monte Carlo) was used to fill in missing values for individual HAQ questions. The normality of variables was evaluated by the Shapiro-Wilk statistics. Correlation coefficients were calculated by the Spearman method. The most important descriptive values were expressed with a 95\% confidence interval (CI). The $\alpha$ level was set at 0.05 for all tests.

\section{RESULTS}

Global health was better and pain less in men than in women (table 1). Other demographic, clinical, and radiological characteristics were similar between the sexes.

Mean total HAQ in men was 0.67 (95\% CI, 0.46 to 0.93 ) and in women 1.08 (0.95 to 1.22). The difference was statistically significant $(p=0.0031)$. Women were more disabled in eating, hygiene, reach, grip, and the common daily activities subdimensions of the HAQ (table 2).

Grip strength was $48 \%$, knee extension strength $46 \%$, trunk extension strength 54\%, and trunk flexion strength $43 \%$ less in female than male rheumatoid patients (table 3 ). Mean (SD) walking time for $10 \mathrm{~m}$ was 6.8 (3.4) s for men and 7.7 (3.2) $\mathrm{s}$ for women $(\mathrm{p}=0.13)$. The corresponding times in the sit-to-stand test were 14.3 (5.7) and $16.5(10.8)(p=0.28)$.

In the whole sample, knee extension strength was inversely correlated with walking time $(r=-0.63$ (95\% CI, -0.73 to -0.51$))$ and the sit-to-stand test $(r=-0.47(-0.60$ to -0.31$)$ ). Further, the total HAQ disability index was strongly associated with walking time and grip strength (fig l).

A higher disease activity (DAS28) and pain score, and lower knee extension and grip strengths entered into the forward ordered logit regression model as an explanatory variable for worse function (higher total HAQ scores) in women, while in men only knee extension strength entered into the model (table 4).

\section{DISCUSSION}

Independent living requires locomotive ability and physical resources. The most reliable evaluation of an individual's functional capacity can be achieved by combining various self assessments of function with direct measurements. ${ }^{28}$ The
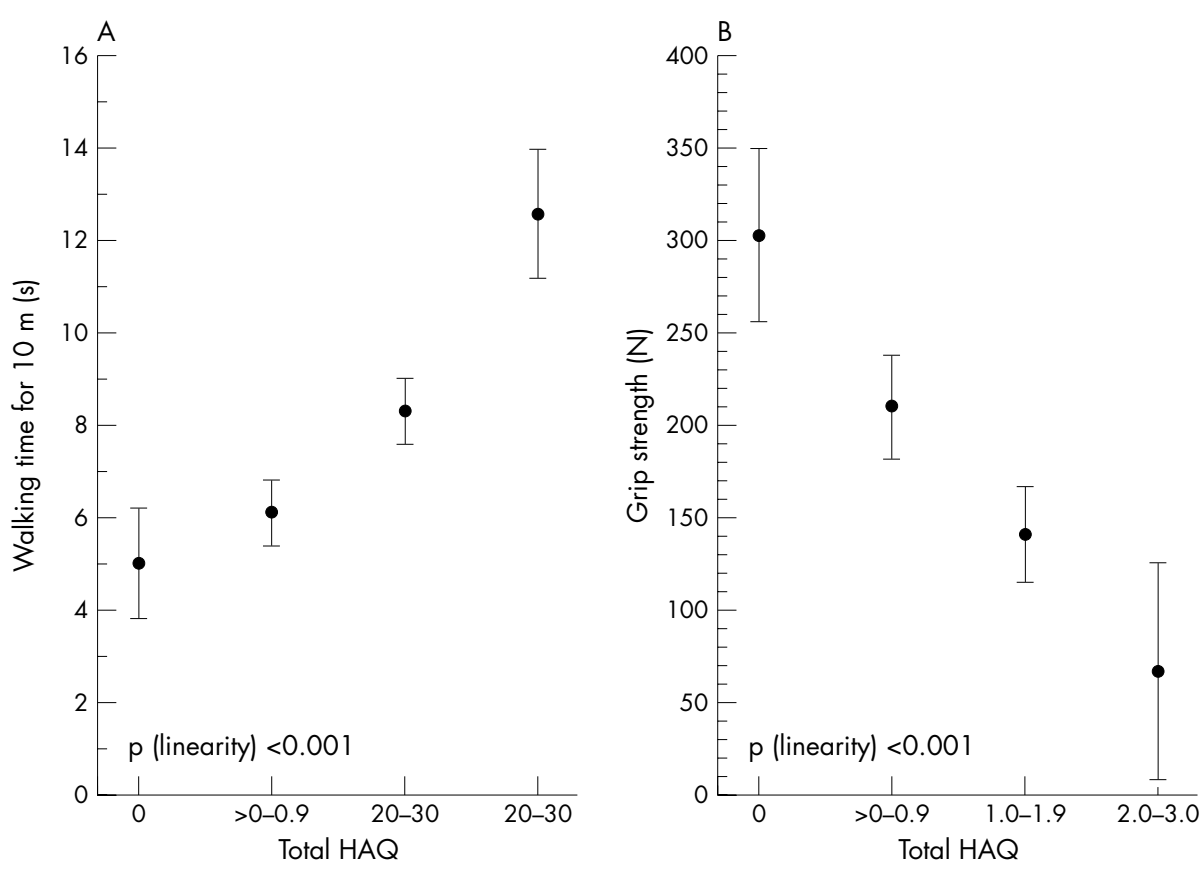

Figure 1 Association between total Health Assessment Questionnaire score and walking time $(A)$ and grip strength (B). Values are means with $95 \%$ confidence intervals. 
Table 4 Ordered logit regression models for odds ratios to Health Assessment Questionnaire in patients with rheumatoid arthritis

\begin{tabular}{|c|c|c|c|c|}
\hline \multirow[b]{3}{*}{ Variable } & \multicolumn{2}{|l|}{ Univariate } & \multicolumn{2}{|l|}{ Multivariate $^{*}$} \\
\hline & Male & \multirow{2}{*}{$\begin{array}{l}\text { Female } \\
\text { OR }(95 \% \mathrm{Cl})\end{array}$} & \multirow{2}{*}{$\begin{array}{l}\text { Male } \\
\text { OR }(95 \% \mathrm{Cl})\end{array}$} & \multirow{2}{*}{$\begin{array}{l}\text { Female } \\
\text { OR }(95 \% \mathrm{Cl})\end{array}$} \\
\hline & OR $(95 \% \mathrm{Cl})$ & & & \\
\hline Age & $1.12(1.04$ to 1.20$)$ & $1.07(1.03$ to 1.11$)$ & & \\
\hline Disease duration & 1.01 (0.96 to 1.07 ) & $1.03(1.00$ to 1.06$)$ & & \\
\hline DAS28 $\geqslant 2.6$ & $2.57(0.74$ to 8.97$)$ & 4.44 (1.91 to 10.37$)$ & & 5.65 (1.85 to 17.28$)$ \\
\hline Erosiveness & 0.85 (0.26 to 2.85$)$ & $2.63(0.90$ to 7.72$)$ & & \\
\hline Pain per $10 \mathrm{~mm}$ & 1.39 (1.14 to 1.68$)$ & 1.25 (1.09 to 1.44$)$ & & $1.37(1.11$ to 1.69$)$ \\
\hline \multicolumn{5}{|l|}{ Strength indices } \\
\hline Knee extension per $50 \mathrm{~N}$ & $0.57(0.40$ to 0.82$)$ & 0.38 (0.29 to 0.52$)$ & 0.57 (0.40 to 0.82$)$ & $0.46(0.30$ to 0.71$)$ \\
\hline Trunk extension per $100 \mathrm{~N}$ & $0.45(0.29$ to 0.69$)$ & $0.45(0.31$ to 0.66$)$ & & \\
\hline Trunk flexion per $100 \mathrm{~N}$ & $0.41(0.19$ to 0.89$)$ & $0.46(0.29$ to 0.74$)$ & & \\
\hline Grip strength per $20 \mathrm{~N}$ & $0.90(0.80$ to 0.99$)$ & 0.76 (0.68 to 0.85$)$ & & $0.81(0.71$ to 0.93$)$ \\
\hline
\end{tabular}

association between muscle strength measurements and functional tests has been described in earlier reports. ${ }^{20} 222930$

In our previous survey the mean HAQ disability index in the general population aged over 30 years was 0.27 (95\% CI, 0.24 to 0.30 ), and $31 \%$ of the respondents reported at least some disability in one of the eight subdimensions of daily living (HAQ $\geqslant 1) .{ }^{31} \mathrm{~A}$ high percentage of rheumatoid patients between the ages of 30 and 70 years perceived worse function than reported by the general population. ${ }^{32}$ In 1982 Fries et al reported a mean total HAQ of 0.80 in 331 rheumatoid patients from a community based population, with an average age of 51 years and a mean duration of disease of 12 years. ${ }^{33}$ We have reported a similar disability (mean $\mathrm{HAQ}=0.92$ ) in rheumatoid patients treated in the rheumatology inpatient ward of our district. ${ }^{34}$ Among the present subjects, mean HAQ was $0.97(95 \% \mathrm{Cl}, 0.85$ to 1.09$)$ and at least some disability was experienced by $87 \%$ of the patients. Thus functional disability among these rheumatoid patients waiting for orthopaedic surgery was both more prevalent and more troublesome than in the general population, while comparable with other studies on rheumatoid patients.

As in our earlier report, ${ }^{32}$ more women than men in the present cohort reported functional problems. It has been suggested that women may overestimate and men underestimate problems of functional capacity and pain. ${ }^{35}{ }^{36}$ On the other hand, the influence of sex on the amount of muscle mass as well as on maximum strength-and thus on the maximum physiological reserve-varies considerably. ${ }^{97}$ In healthy women maximum strength has been reported to be about $52-80 \%$ of that in men. ${ }^{98} 39$ In the present study the strength of different muscle groups was $52-57 \%$ lower in women than in men with rheumatoid arthritis. Thus the weaker muscles in women with rheumatoid arthritis may make them more vulnerable to functional deficit.

Previous studies have shown significant and progressive loss of grip strength in rheumatoid patients over time. ${ }^{4041}$ Significant correlations between grip strength and the self reported global HAQ function have also been found. ${ }^{42}{ }^{43}$ In our earlier study we showed that grip strength can explain perceived performance in the subdimensions of "eating," "reach," "grip," and "common daily activities" of the HAQ. ${ }^{34}$ In the present patients, with their considerably longer disease duration but lower disease activity, grip strength was associated with the same subdimensions of the HAQ that require the ability to grip. Particularly in women, the detected grip strength level (about half of that in males) might be very close to or even below to that required, for example, to open a milk cartoon or cut meat, while men, despite having impaired grip strength values, still have strength well above the required level.
In the present study we also found that decreased knee extension strength was associated with walking speed and sit-to-stand tests in both women and men with rheumatoid arthritis. The sit-to-stand test or the HAQ item "stand up from a straight chair" shows whether the strength level of the knee extensors is adequate or inadequate for chair rise, but it does not provide any information about the amount of an individual's muscle strength reserve. ${ }^{44} 45$ Hughes et al reported that older people used $97 \%$ of their maximum knee extension strength to get up from a $33 \mathrm{~cm}$ high chair. ${ }^{46} \mathrm{In}$ contrast, their younger subjects used only 39\% of their maximum strength. Ferrucci L et al have reported that knee extension strength below $10 \mathrm{~kg}$ limits the ability to rise from a chair. ${ }^{47}$ Further, they reported that better strength was associated with better balance.

Pain, stiffness, fatigue, biomechanical deficiencies, and gait deviations may reduce the locomotive capacity of rheumatoid patients. Independent and safe locomotion in the community reportedly requires as a prerequisite a walking speed of $1.4 \mathrm{~m} /$ $\mathrm{S}^{47}$ while carrying out activities of daily living at home requires a walking speed of at least $0.4-0.5 \mathrm{~m} / \mathrm{s} \cdot{ }^{40}{ }^{44}$ In our present study $45 \%$ of the patients had a walking speed less than $1.4 \mathrm{~m} / \mathrm{s}$, showing that their ability to walk safely may also be at risk. Consequently, if patients' walking ability is impaired, they cannot be physically active enough to produce the heart and ventilation rates needed to maintain or improve cardiovascular capacity. When all daily activities are carried out slowly and with low effort, the reserve in performance capacity fades. Then, even a small additional strain may lead to a situation where the patient's independent living becomes endangered or even impossible. Decreased physical activity in turn may gradually lead to obesity, accelerated atherosclerosis, and ultimately to increased comorbidity and mortality in rheumatoid patients. ${ }^{45} 46$ On the other hand, those with a greater strength reserve may lose even more strength without the threat of crossing the threshold of disability. In the HAQ questionnaire the manner in which the tasks are to be performed is not defined (for example, walking speed, standing up with or without using arms to push off), and thus in everyday life patients may compensate the strength or mobility deficits by using various strategies without becoming conscious of their falling reserve capacity.

The pain level in our present rheumatoid patients waiting for surgery was comparable to that in our earlier report. ${ }^{18}$ Increases in all eight subdimensions of the HAQ could be explained by pain, suggesting that in part the HAQ measures similar disability constructs to those assessed by the pain scale. ${ }^{32}$ In the present study perceived pain was also a significant explanatory factor for greater disability in women. Musculoskeletal pain inhibits the motor system and thus 
prevents or decreases the intensity of muscle contraction during the peak pain, even after the disappearance of the pain sensation. ${ }^{47}$ Arthritic, injured, and inflamed joints may also cause reflex inhibition without perceived pain. ${ }^{47}$ A major issue, however, is that rheumatoid patients may avoid strain on account of pain, which in the long run leads to decreased muscle strength and functional capacity.

Generalisation of these results can only be tentative, as the patients participating in our study represent individuals with relatively longstanding rheumatoid arthritis. Further, the number of men was rather small, although their relative proportion $(29 \%)$ equalled the prevalence of rheumatoid arthritis in men in the population.

In summary, the results indicate that female patients with rheumatoid arthritis report greater disability than male patients, both in the total HAQ disability index and in the majority of its subdimensions. In addition to pain and clinical disease activity, muscle strength has a major impact on physical function.

\section{Authors' affiliations}

A Häkkinen, J Ylinen, Departments of Physical Medicine and Rehabilitation, Jyväskylä Central Hospital, Jyväskylä, Finland P Hannonen, H Mäkinen, T Sokka, Department of Medicine, Jyväskylä Central Hospital

H Kautiainen, Rheumatism Foundation Hospital, Heinola, Finland

T Sokka, Vanderbilt University, Nashville, Tennessee, USA

\section{REFERENCES}

1 Janssen I, Heymsfield SB, Wang ZM, Ross R. Skeletal muscle mass and distribution in 468 men and women aged 18-88 yr. J Appl Physiol 2000;89:81-8.

2 Kehayias JJ, Fiatarone MA, Zhuang $\mathrm{H}$, Roubenoff R. Total body potassium and body fat: relevance to aging. Am J Clin Nutr 1997;66:904-10.

3 Lexell J, Downham D, Sjostrom M. Distribution of different fibre types in human skeletal muscles. Fibre type arrangement in $\mathrm{m}$. vastus lateralis from three groups of healthy men between 15 and 83 years. J Neurol Sci 1986;72:211-22.

4 Janssen I, Baumgartner RN, Ross R, Rosenberg IH, Roubenoff R. Skeletal muscle cutpoints associated with elevated physical disability risk in older men and women. Am J Epidemiol, 2004;15, 159:413-21.

5 Frontera WR, Hughes VA, Lutz KJ, Evans WJ. A cross-sectional study of muscle strength and mass in 45- to 78-yr-old men and women. J Appl Physiol 1991;71:644-50.

6 Metter EJ, Lynch N, Conwit R, Lindle R, Tobin J, Hurley B. Muscle quality and age: cross-sectional and longitudinal comparisons. J Gerontol A Biol Sci Med Sci 1999;54:B207-18.

7 Frontera WR, Hughes VA, Fielding RA, Fiatarone MA, Evans WJ, Roubenoff R. Aging of skeletal muscle: a 12-yr longitudinal study. J Appl Physiol 2000;88: 1321-6.

8 Rantanen T, Guralnik JM, Ferrucci L, Penninx BW, Leveille S, Sipila S, et al. Coimpairments as predictors of severe walking disability in older women. J Am Geriatr Soc 2001;49:21-7

9 Stoll T, Huber E, Seifert B, Michel BA, Stucki G. Maximal isometric muscle strength: normative values and gender-specific relation to age. Clin Rheumatol 2000;19:105-13.

10 Rall LC, Roubenoff R. Rheumatoid cachexia: metabolic abnormalities, mechanisms and interventions. Rheumatology (Oxford) 2004;43:1219-23.

11 Hsieh L, Detenko B, Schumacher H. Isokinetic and isometric testing of knee musculature in patients with rheumatoid arthritis with mild knee involvement. Arch Phys Med Rehab 1987;68:294-7.

12 Ekdahl C, Broman G. Muscle strength, endurance, and aerobic capacity in rheumatoid arthritis: a comparative study with healthy subjects. Ann Rheum Dis 1992;51:35-40

13 Häkkinen A, Hannonen P, Häkkinen K. Muscle strength in healthy people and in patients suffering from recent-onset inflammatory arthritis. $\mathrm{Br} J$ Rheumatol 1995;34:355-60.

14 Nordesjo LO, Nordgren B, Wigren A, Kolstad K. Isometric strength and endurance in patients with severe rheumatoid arthritis or osteoarthrosis in the knee joints. A comparative study in healthy men and women. Scand J Rheumatol 1983; 12:152-6.

15 Pincus T, Callahan LF, Brooks RH, Fuchs HA, Olsen NJ, Kaye JJ. Self-report questionnaire scores in rheumatoid arthritis compared with traditional physical, radiographic, and laboratory measures. Ann Intern Med, 1989;15, 110:259-66.

16 Sokka T, Kankainen A, Hannonen P. Scores for functional disability in patients with rheumatoid arthritis are correlated at higher levels with pain scores than with radiographic scores. Arthritis Rheum 2000;43:386-9.

17 Welsing PM, van Gestel AM, Swinkels HL, Kiemeney LA, van Riel PL. The relationship between disease activity, joint destruction, and functional capacity over the course of rheumatoid arthritis. Arthritis Rheum 2001;44:2009-17.
18 Guillemin F, Suurmeijer T, Krol B, Bombardier C, Briancon S, Doeglas D, et al. Functional disability in early rheumatoid arthritis: description and risk factors. J Rheumatol 1994;21:1051-5.

19 Drossaers-Bakker KW, Kroon HM, Zwinderman AH, Breedveld FC, Hazes JM. Radiographic damage of large joints in long-term rheumatoid arthritis and its relation to function. Rheumatology (Oxford) 2000;39:998-1003.

20 Stucki G, Bruhlmann P, Stucki S, Michel BA. Isometric muscle strength is an indicator of self-reported physical functional disability in patients with rheumatoid arthritis. Br J Rheumatol 1998;37:643-8.

21 Hakala $M$, Nieminen $P$, Koivisto $O$. More evidence from a community based series of better outcome in rheumatoid arthritis. Data on the effect of multidisciplinary care on the retention of functional ability. J Rheumatol 1994;21:1432-7.

22 Jette A, Jette D, $\mathrm{Ng} \mathrm{J}$, Plotkin D, Bach M, and the Musculoskeletal Impairment Study Group. Are performance-based measures sufficiently reliable for use in multicenter trials? J Gerontol A Biol Sci Med Sci 1999;54:M3-6.

23 Hakkinen $\mathrm{K}$, Alen $M$, Kallinen $M$, Izquierdo $M$, Jokelainen $K$, Lassila $H$, et al. Muscle CSA, force production, and activation of leg extensors during isometric and dynamic actions in middle-aged and elderly men and women. $J$ Aging Phys Act 1998;6:232-47.

24 Rantanen P, Airaksinen O, Penttinen E. Paradoxical variation of strength determinants with different rotation axes in trunk flexion and extension tests. Eur J Appl Physiol 1994;68:322-6.

25 Mathiowetz V, Candidate PD. Reliability and validity of grip and pinch strength measurements. Phys Rehab Med 1991;4:201-12.

26 Price D, McGrath P, Rafii A, Buckingham $B$. The validation of visual analogue scales as ratio scale measures for chronic and experimental pain. Pain 1983;17:45-56.

27 Prevoo M, van't Hof M, Kuper H, van Leeuwen $M$, van de Putte L, van Riel P. Modified disease activity scores that include twenty-eight-joint counts. Arthritis Rheum 1995:38:44-8.

28 Guralnik JM, Ferrucci L. Assessing the building blocks of function: utilizing measures of functional limitation. Am J Prev Med 2003;25(3 suppl 2): 112-21.

29 Rantanen T, Guralnik JM, Foley D, Masaki K, Leveille S, Curb JD, et al. Midlife hand grip strength as a predictor of old age disability. JAMA $1999 ; 281: 558-60$

30 Schrenkman M, Huges M, Samsa G, Studenski S. The relative importance of strength and balance in chair rise by functionally impaired older individuals. J Am Geratr Soc 1996:44:1441-6.

31 Krishnan E, Sokka T, Häkkinen A, Hubert H, Hannonen P. Normative values for the Health Assessment Questionnaire disability index: benchmarking disability in general population. Arthritis Rheum, 2004;50, 3:953-60.

32 Sokka T, Krishnan E, Hakkinen A, Hannonen P. Functional disability in rheumatoid arthritis patients compared with a community population in Finland. Arthritis Rheum 2003;48:59-63.

33 Fries J. The dimensions of health outcomes: the Health Assessment Questionnaire disability and pain scales. J Rheumatol 1982:9:789-93.

34 Hakkinen A, Kautiainen $\mathrm{H}$, Hannonen P, Ylinen J, Arkela-Kautiainen M, Sokka T. Pain and joint mobility explain individual subdimensions of the Health Assessment Questionnaire (HAQ) disability index in patients with rheumatoid arthritis. Ann Rheum Dis. 2005;64: 59-63, Epub 2004 May 06.

35 Rantanen T, Masaki K, Foley D, Izmirlian G, White L, Guralnik JM. Grip strength changes over $27 \mathrm{yr}$ in Japanese-American men. J Appl Physiol 1998;85:2047-53.

36 Wingard DL. The sex differential in morbidity, mortality, and lifestyle. Annu Rev Public Health 1984;5:433-58.

37 Pedersen AN, Ovesen L, Schroll M, Avlund K, Era P. Body composition of 80years old men and women and its relation to muscle strength, physical activity and functional ability. J Nutr Health Aging 2002;6:413-20.

38 Sinaki M, Nwaogwugwu NC, Phillips BE, Mokri MP. Effect of gender, age, and anthropometry on axial and appendicular muscle strength. Am J Phys Med Rehabil 2001;80:330-8.

39 Miller AE, MacDougall JD, Tarnopolsky MA, Sale DG. Gender differences in strength and muscle fiber characteristics. Eur J Appl Physiol Occup Physiol 1993;66:254-62.

40 Pincus T, Callahan LF. Rheumatology function tests: grip strength, walking time, button test and questionnaires document and predict longterm morbidity and mortality in rheumatoid arthritis. J Rheumatol 1992;19:1051-7.

41 Hakala M, Nieminen P, Koivisto $O$. More evidence from a community based series of better outcome in rheumatoid arthritis. Data on the effect of multidisciplinary care on the retention of functional ability. J Rheumatol 1994;21:1432-7

42 Jantti JK, Kaarela K, Luukkainen RK, Kautiainen HJ. Prediction of 20-year outcome at onset of seropositive rheumatoid arthritis. Clin Exp Rheumato 2000; 18:387-90.

43 Pincus T, Callahan LF. Rheumatology function tests: grip strength, walking time, button test and questionnaires document and predict long-term morbidity and mortality in rheumatoid arthritis. J Rheumatol 1992;19:1051-7.

44 Chandler J, Duncan P, Studenski S. Choosing the best strength measure in fair older persons: importance of task specificity. Muscle Nerve 1997;5:49-51.

45 Rantanen T. Muscle strength, disability and mortality. Scand J Med Sci Sports 2003;13:3-8.

46 Hughes M, Myers B, Schrenkman M. The role of strength in rising from chair in the functionally impaired elderly. J Biomechanics 1996;12:1509-13.

47 Ferrucci L, Guralnic J, Buchner D, Kasper J, Lamb S, Simonsick E, et al. for the WHAS Research Group. Departures from linearity in the relationship between measures of muscular strength and physical performance of the lower extremities: the women's health and aging study, J Geront Med Sci 1997;52A:M275-85. 